\title{
A falsa pista de um cego teimoso
}

\author{
CAio Gagliardi \\ Universidade de São Paulo (São Paulo, Brasil)
}

RESUMO: O QUE ACONTECERIA COM A MINHA PERCEPÇÃO DO MUNDO SE EU NÃO TIVESSE MEMÓRIA? COM BASE NA QUESTÃO PRELIMINAR DESTE ENSAIO, SEU OBJETIVO É PROPOR UMA LEITURA DO POEMA "O GUARDADOR DE REBANHOS", DE ALBERTO CAEIRO. A EXEMPLO DAS OBRAS DE EMPIRISTAS COMO LOCKE, HUME E, ESPECIALMENTE, CONDILLAC, PARA QUEM TODO O CONHECIMENTO E TODAS AS FACULDADES INTELECTUAIS DERIVAM DAS SENSAÇÕES, A OBRA DE CAEIRO DRAMATIZA A IMPOSSIBILIDADE DE CONHECER O MUNDO EXCLUSIVAMENTE POR MEIO DOS SENTIDOS.

ABSTRACT: WHAT WOULD HAPPEN TO MY PERCEPTION OF THE WORLD IF I HAD NO MEMORY? BEARING THIS PRELIMINARY QUESTION IN MIND, THIS ARTICLE AIMS TO ANALYZE ALBERTO CAEIRO'S POEM "THE KEEPER OF SHEEP". AS IN THE THOUGHT OF EMPIRICISTS SUCH AS LOCKE, HUME AND, ESPECIALLY, CONDILLAC, FOR WHOM ALL KNOWLEDGE AND ALL OUR INTELLECTUAL FACULTIES HAVE THEIR ORIGIN IN SENSATIONS, CAEIRO'S WORK DRAMATIZES THE IMPOSSIBILITY OF KNOWING THE WORLD EXCLUSIVELY THROUGH THE SENSES.

KEYWORDS: ALBERTO CAEIRO, "THE KEEPER OF SHEEP", CONDILLAC, MERLEAUPONTY, INTERTEXTUALITY.

PALAVRAS-CHAVE: ALBERTO CAEIRO, "O GUARDADOR DE REBANHOS", CONDILLAC, MERLEAU-PONTY, INTERTEXTUALIDADE. 
Porque me falta a simplicidade divina

De ser todo só o meu exterior

Alberto Caeiro.

que aconteceria à minha percepção do mundo se eu não possuísse memória?

Não creio ser comum nos fazermos essa pergunta ao lermos os poemas de "O Guardador de Rebanhos", embora eles estejam repletos de considerações a esse respeito.

Nas "Notas para a recordação do meu mestre Caeiro", Álvaro de Campos atribui a seguinte afirmação a Caeiro: "Toda coisa que vemos, devemos vê-la sempre pela primeira vez, porque realmente é a primeira vez que a vemos". (Presença, jan.-fev., 1931) Para que a mesma coisa permaneça eternamente nova, há duas possibilidades: uma delas é possuir uma percepção infalível, a exemplo da de Irineu Funes, a enigmática personagem de Borges, a ponto de conferir ao sujeito sensitivo a capacidade de identificar a mais sutil alteração em um ser ou objeto, ocasionada simplesmente pela passagem do tempo: "aborrecia-o que o cão das três e catorze (visto de perfil) tivesse o mesmo nome que o cão das três e quarto (visto de frente). Seu próprio rosto no espelho, suas próprias mãos, surpreendiam-no todas as vezes.” (BORGES, 1999, p. 545) A outra possibilidade é imaginar, justamente, um sujeito diametralmente oposto a Funes, isto é, alguém que simplesmente não possua o menor vestígio de memória. Sem memória, o absurdo da condição moderna, do homem condenado a repetir a vida toda a mesma tarefa, representado por Camus na condenação de Sísifo, se torna menos trágico: "Este mito só é trágico porque seu herói é consciente”. (CAMUS, 2004, p. 139). O mesmo que Camus afirma a respeito de Sísifo pode ser dito sobre Caeiro, herói consciente que, no entanto, se pretende inconsciente. É justamente essa tensão, afinal, que este ensaio irá explorar.

O diálogo constante entre Campos e Caeiro nos remete ao Teeteto, de Platão, através do qual entrevemos por refutações a grandeza do pensamento de Heráclito, segundo o qual tudo muda; seriam dele afirmações célebres como a que diz que o sol é novo a cada dia, ou que não se pode entrar duas vezes no mesmo rio. A objetualidade caeiriana, a exemplo da doutrina do fluxo permanente, 
de Heráclito, não é a lamentação ou busca da suspensão do tempo, como à que conduziram a poesia lírico-amorosa ou o pensamento cristão; pelo contrário, é uma forma de enfatizar a eterna novidade da realidade presente.

Em "O Guardador de Rebanhos", Fernando Pessoa nos apresenta um eu lírico que diz atravessar a vida sem olhar "para trás de si e tendo pena", que procura encarar o mundo, em síntese, em seu aqui (bic) e agora (et nunc). O vento, afirma Caeiro, não fala de "memória e de saudades", "só fala de vento".

Considerando bem, e ao contrário do que se poderá pensar, essa visão de mundo não é agnóstica; para um agnóstico o fundo das coisas não pode ser conhecido pelo espírito humano. O sujeito dos poemas-Caeiro é, ao contrário, um sujeito cognoscente, ele conhece o mundo porque, a seu ver, a essência das coisas reside em sua aparência ("[...] o único sentido oculto das coisas / é elas não terem sentido oculto nenhum”), e é apreensível pelos sentidos ("Sim, eis o que os meus sentidos aprenderam sozinhos: - / As cousas não têm significação, têm existência.”).

A primeira estrofe do poema II do "Guardador de Rebanhos" trata do olhar original, que faz de cada instante um momento nunca antes visto. Se renascêssemos continuamente, não teríamos o que recordar, e, portanto, a nossa percepção do mundo seria sempre única:

II

O meu olhar é nítido como um girassol.

Tenho o costume de andar pelas estradas

Olhando para a direita e para a esquerda,

E de vez em quando olhando para trás...

E o que vejo a cada momento

É aquilo que nunca antes eu tinha visto,

$\mathrm{E}$ eu sei dar por isso muito bem...

Sei ter o pasmo essencial

Que tem uma criança se, ao nascer,

Reparasse que nascera deveras...

1. As citações são todas retiradas de Pessoa, Fernando. Poemas completos de Alberto Caeiro. Introdução de Caio Gagliardi. São Paulo: Hedra, 2011. 
Sinto-me nascido a cada momento

Para a eterna novidade do Mundo...

Para que esse "pasmo essencial" se renove perpetuamente, é preciso esquecer o que se viu. A utopia imaginada por Pessoa é a de um mundo absoluto, que traz em si a própria razão de ser. As coisas e os acontecimentos, uma pedra, o rio que corre são um todo em si e por si, porque, segundo o panteísmo caeiriano, se Deus está na natureza, e se Deus é Ser Absoluto, então não há porque pensar que a existência de uma coisa derive da existência de outra. A Natureza não são partes de um todo, assim fosse atribuir-se-ia à ideia de "todo" uma dimensão metafísica. A natureza é o todo em cada parte, em cada coisa. A eliminação da noção de "parte" dessa perspectiva é uma decorrência, afinal, da anulação da memória: a parte só pode ser assim considerada à luz da memória de um todo.

A busca da objetualidade do mundo está condicionada pela apreensão da realidade exterior pelos sentidos, e os sentidos, por si mesmos, não estabelecem relações entre as coisas. Se formos capazes de nos lembrar daquilo que percebemos anteriormente, preterimos em parte do mundo exterior e nos ensimesmamos em nossas sensações passadas - e sensações passadas são sensações sobre o que não percebemos mais. Para Caeiro, o que não está mais presente não existe para os sentidos, porque o seu resgate é intelectual e não sensorial ("lembrar não é ver").

\section{XLIII}

Antes o vôo da ave, que passa e não deixa rasto, Que a passagem do animal que fica lembrada no chão.

A ave passa e esquece, e assim deve ser.

O animal, onde já não está e por isso nada serve,

Mostra que já esteve, o que não serve para nada.

A recordação é uma traição à Natureza,

Porque a Natureza de ontem não é Natureza.

O que foi não é nada, e lembrar é não ver.

Passa, ave, passa, e ensina-me a passar! 
A rigor, o que Pessoa projeta em Caeiro é o desejo de desarticular a sensação da memória, de anulá-la, e de, então, sem atribuir-lhes qualquer significação, encerrar-se nos sentidos.

Caeiro escuta mal, inala odores abstratos, quase não tem paladar, e sua percepção tátil é comparável à de um primata. Ele é praticamente só visão (“O essencial é saber ver”. Ou então: “[...] a nossa única riqueza é ver.”). A hipótese de um indivíduo em quem os sentidos não se somam ou concorrem entre si, de alguém que não se lembra de suas sensações, e que não lhes atribui significados, não difere, como ideal perceptivo, do que Bergson definiu por sensação pura. E isso nos leva a inquirir sobre que tipo de mundo e de sujeito decorreria dessa experiência. O Alberto Caeiro cuja imagem psicológica nos chega dos poemas é, evidentemente, muito mais complexo do que o "animal humano" desaculturado e empobrecido tal como descrevi, mas o Caeiro (a utopia) que seria produzido dessa experiência seria um organismo intuitivo, um espécime instantâneo, sem consciência de si, e constituído inteiramente à imagem e semelhança do objeto percepcionado. A suposição que MerleauPonty faz nesse mesmo sentido lança luz sobre essa possibilidade:

Se quero encerrar-me em um dos meus sentidos e, por exemplo, me projeto inteiro em meus olhos e abandono-me ao azul do céu, em breve não tenho mais consciência de olhar e, no momento em que queria fazer-me inteiro visão, o céu deixa de ser uma "percepção visual" para tornar-se meu mundo do momento. (MERLEAU-PONTY, 1999, p. 304)

A consciência só opera a partir da abstração do percepcionado, ou seja, de sua lembrança. Sem memória, portanto, eu sou incapaz de tornar-me consciente, o que implica dizer que perco a habilidade de conceber a mim mesmo como sujeito perceptivo. Essa hipótese possibilita o mergulho na calma da consubstanciação. Em outras palavras, através da anulação da memória eu me torno aquilo que vejo:

O meu olhar azul como o céu

É calmo como a água ao sol.

É assim, azul e calmo,

Porque não interroga nem se espanta... 
Bergson acreditava que o sujeito mediante podia fundir-se ao objeto sobre o qual ele medita, e o saber dilatar-se a ponto de confundir-se com o ser. Isso significa o mesmo que considerar, como aventa Merleau-Ponty, que o pensamento objetivo ignora o sujeito da percepção. A experiência da pura sensação implicaria a total indiferenciação entre o eu que sente e o sentir em si mesmo. O ideal-Caeiro é análogo à intuição bergsoniana: ambos conduzem para o apagamento da consciência, ou do sujeito mediante. Consiste, por isso, num ideal de libertação, que visa, através da anulação da memória, à cessação das inquietações, isto é, à transformação do sujeito sensitivo na própria sensação. No poema VII, Caeiro afirma: "Porque eu sou do tamanho do que vejo / E não do tamanho da minha altura [...]”. Quem está por trás da afirmação “eu sou", ou simplesmente o eu lírico Caeiro, sujeito mnemônico e raciocinante, desenha nos poemas d"'O Guardador de Rebanhos" um ideal-Caeiro, ou o objeto "eu", elaborado como um negativo do ortônimo. Essa máscara de si mesmo inverte a metáfora-base do Cancioneiro: o arquicaeiro desejado, estado assim idealizado pelo eu lírico, se constitui, se pudermos parodiar a conhecida expressão, como um "novelo virado para fora".

Essa é a proposta de um empirismo radical estranho ao pano de fundo cultural tecido durante a escrita dessa poesia. Pessoa, em um de seus fragmentos teóricos, afirma: "Como interpretar esta época, opondo-se-lhe" (PESSOA, 1966, p. 167). Por isso é costume entre os críticos referir-se à poesia-Caeiro como uma reação a alguma corrente dominante a partir dos fins do sec. XIX - de onde se originaram o "anti-decadentismo", o "antissaudosismo" e o "anti-transcendentalismo" de Caeiro. Por uma via reativa a esta, esforços feitos no sentido de situar essa poesia não apenas como rejeição de algo resultaram em verdadeiros achados críticos, como a interpretação judaico-cristã de Maria Helena Nery Garcez, que tem como base a intertextualidade com São Francisco de Assis (GARCEZ, 1985) e a estimulante abordagem de Leyla Perrone-Moisés, que associa, como procedimento de leitura, Caeiro com o zen-budismo (PERRONE-MOISÉS, 2001).

O empirismo que Pessoa formula para produzir uma das imagens de Caeiro está claramente respaldado num sistema teórico de ideias esparsas, eivado de contradições e passagens de força poética, referido por sensacionismo. Num texto intitulado "Modernas correntes da literatura portuguesa", Álvaro de Campos afirma ser "o sr. Alberto Caeiro" o "chefe" do sensacionismo. Em 
outro fragmento sobre o sensacionismo, encontramos: "Fundou-O Alberto Caeiro, o mestre glorioso..." (CAMPOS, 1966, p. 169) A poesia de Pessoa, seja a tipificada como "heteronímica", seja a que ele assina com o próprio nome, está fortemente relacionada com as ideias sensacionistas. Ela é, em grande parte, a formulação poética dessas ideias. Por esse motivo, superada a fase inicial de sua recepção crítica, que se pautara numa noção ainda superficial de "sinceridade artística", 2 não foram poucos os críticos que preferiram interpretá-la à luz das considerações teóricas de Pessoa. Para o bem e para o mal, o crítico alemão Georg Rudolf Lind (1970) talvez seja, ainda hoje, aquele que mais tenha contribuído para que se leia Fernando Pessoa como um autor programático, na mesma esteira de outros epígonos modernistas, como Mallarmé, Valéry, Eliot e Pound. José Gil (1987), por outra via, aprofundou com considerável êxito o ideário sensacionista, mas, cooptando-o, quis resolvê-lo, com base na poesia e nos textos teóricos.

Essas considerações permitem enxergar que a poesia-Caeiro não surge apenas como reação ao seu tempo; ela é a afirmação de algo que tem respaldo nas tradições dos pensamentos ocidental e oriental, bem como na própria tradição literária portuguesa. Nesse sentido, é uma leitura possivelmente produtiva para os interesses deste ensaio confrontar Caeiro com as investigações filosóficas de Étienne de Condillac, em quem o empirismo encontrou uma de suas formulações mais originais.

\section{II}

A tarefa investigativa de Condillac foi precedida de perto pela obra nãopolítica de Locke, em especial a vinculada à sua teoria do conhecimento. Locke atribuiu à sensação e à reflexão a fonte de nossas ideias. No Ensaio acerca do entendimento humano, ele defende que todo o nosso conhecimento deriva da experiência, que é empregada tanto nos objetos sensíveis externos como

2. Refiro-me à tríade presencista: José Régio, que embora não tenha importância direta na recepção crítica de Pessoa, escreveu o primeiro artigo sobre o poeta e foi um dos mentores intelectuais do presencismo; João Gaspar Simões, autor de Vida e Obra de Fernando Pessoa - bistória duma geração. 6a. Edição. Lisboa: Publicações Dom Quixote, 1991; e Adolfo Casais Monteiro, autor de Estudos sobre a poesia de Fernando Pessoa. Rio de Janeiro: Agir, 1958. 
nas operações mentais internas. Sua filosofia é conduzida, claro está, como refutação à tradição imanentista: "Embora a posse de ideias gerais, o uso de palavras gerais e a razão geralmente cresçam juntos, não vejo como isto possa de algum modo prová-las inatas”.(LOCKE, 1973, p. 154) Para demonstrar como suprimos e ativamos a nossa mente de qualidades e operações, Locke imaginou um cego de nascença a quem seria atribuído o sentido da visão, e passou a especular sobre suas reações.

Num texto quase homônimo ao de Locke, David Hume, contemporâneo de Condillac, supõe uma situação oposta à imaginada por ele, mas que conduz para o mesmo fim: como reagiria uma pessoa que, "dotada das mais vigorosas faculdades de razão e reflexão", fosse trazida repentinamente ao nosso mundo? Hume afirma que esse indivíduo, sem experiências armazenadas, seria incapaz de identificar relações de causa e efeito, porque essas relações não são apreensíveis pelos sentidos. Ele veria acontecimentos que se sucedem simplesmente, sem inferir a existência de um do aparecimento do outro. Mas, com o tempo, verificaria que determinadas sucessões se repetem, e observaria uma conjunção constante entre os objetos, o que lhe tornaria propenso a esperar que algumas sucessões viessem a se estabelecer. Se o raciocínio desse indivíduo não foi capaz de inferir as relações que, desde a primeira ocorrência por ele observada, já existiam, é porque, segundo Hume, essas inferências são efeito do costume, e não do raciocínio: "O hábito é, pois, o grande guia da vida humana. É aquele princípio único que faz com que nossa experiência nos seja útil e nos leve a esperar, no futuro, uma sequência de acontecimentos semelhantes às que se verificaram no passado" (HUME, 1973, p. 146).

É desnecessário me estender no estudo dessas obras para afirmar apenas que a minha leitura, necessariamente fragmentária, de Locke e Hume, ilustra um consenso histórico: de que eles estão em evidente oposição ao cogito cartesiano. O racionalismo de Descartes direciona o trabalho da consciência sobre si mesma (o eu cartesiano é puro pensamento), ao passo que o ponto de vista empirista volta a consciência para o mundo exterior, apreensível por um eu sensível. A minha leitura da poesia-Caeiro depende dessas considerações, porque tenta mostrar que ela está instalada numa zona de tensão entre dois modos opostos de ver o mundo, um que pode ser referido como tipicamente empirista, o outro como racionalista. O que me parece axial para que se compreenda Caeiro, é considerar que sua gênese, conduzida para além da 
solicitação de seu criador na "carta sobre a gênese dos heterônimos", pode ser mais bem descrita como um tour de force de Pessoa por esse fértil terreno da teoria do conhecimento.

Quando Condillac começou a elaborar sua obra, Locke e Hume haviam tecido um pano de fundo consistente, a partir de longas objeções ao metafisicismo de Platão e ao imanentismo de Descartes e de toda a filosofia escolástica. Embora a sua importância seja consideravelmente menor que a de Locke, com quem partilhou boa parte das suas noções sobre produção de conhecimento e desenvolvimento das faculdades do espírito, Condillac radicalizou-as ao considerar que os sentidos são a fonte única de nosso saber. Em outros termos: que também as operações mentais são fruto das sensações. O Tratado das Sensações é a sua obra principal. Ali, Condillac atribui à experiência, aos fatos sensíveis, o conhecimento que temos: "O principal objetivo desta obra é mostrar como todos os nossos conhecimentos e todas as nossas faculdades vêm dos sentidos, ou, para falar mais exatamente, das sensações [...]" (CONDILLAC, 1993, p. 31).

A análise das sensações é o substrato único do Tratado. À sua semelhança formulam-se as assertivas tipicamente empiristas de Fernando Pessoa sobre o sensacionismo: "Todo o objeto é uma sensação nossa" (1966, p.168); “O sensacionismo afirma, primeiro, o princípio da primordialidade da sensação - que a sensação é a única realidade para nós" (Ibid., p.190); "There is no reality but sensation" (Ibid., p.183); "The only reality in life is sensation. The only reality in art is consciousness of the sensation" (Ibid., p.130).

Parent work de "O Guardador de Rebanhos", o Tratado das Sensações é fruto da proeza imaginativa de Condillac, que procura demonstrar, a partir de uma ficção metodológica, como adquirimos o uso de nossas faculdades. Condillac imagina uma estátua organizada interiormente como um ser humano que fosse desprovido de ideias. Ele supõe que ela esteja revestida de mármore, para que os seus sentidos permaneçam isolados do mundo exterior, e que esse revestimento contenha canais que possibilitem, de acordo com a vontade do autor, a abertura de determinado sentido para o mundo exterior. Da descrição do mundo percebido pelos sentidos, isoladamente e em conjunto, resulta a tentativa de demonstrar que a constituição do nosso ser tal como é deriva das sensações.

Nesse sentido, o percurso de Condillac é especialmente significativo para se pensar a poesia d"“O Guardador de Rebanhos". A personagem Caeiro é 
qualificada por Pessoa como sendo a fundadora do sensacionismo, embora devamos ler a frase inversamente: os escritos de teor sensacionista é que dão origem ao ideal-Caeiro. Esse título decorre menos de uma eleição, digamos, em segunda instância de Pessoa, do que, efetivamente, da presença de uma profissão de fé sensacionista no "Guardador de Rebanhos". Ali, o eu lírico afirma categoricamente: "Eu não tenho filosofia: tenho sentidos...". Assim sendo, o ato de escrever significa, já de partida, uma contrariedade, porque não se escreve somente com os sentidos. Daí a explicação: "Como se escrever fosse uma coisa que me acontecesse". O eu lírico escreve como se consubstanciasse, ou melhor, como se quisesse consubstanciar - sem a interferência do pensamento, portanto - as suas sensações.

Procuro dizer o que sinto

Sem pensar o que sinto.

Procuro encostar as palavras à ideia.

Mas essa tarefa será menos possível à medida que se torne mais necessário refletir sobre ela. Diante dos silogismos e dos paradoxos insolúveis com que se depara, e da considerável distância que a poesia realizada se encontra de seu suposto ideal empirista ("suposto", porque nada prova que Pessoa não pretendesse mesmo uma poesia contraditória e eivada de tensões, e que não seja o ideal-Caeiro uma falsa pista, como as inúmeras que ele nos forneceu), o sujeito desses poemas chegará a ponto de produzir autocrítica, que é também uma confissão da impossibilidade de realizar aquilo que diz pretender:

E assim escrevo, ora bem, ora mal,

Ora acertando com o que quero dizer, ora errando,

Caindo aqui, levantando-me acolá

Mas indo sempre no meu caminho como um cego teimoso.

A "teimosia" de Pessoa não é cega, no entanto, e resulta de procedimentos distintos durante a manutenção desse eu desintelectualizado. No poema XXXVII, o eu lírico confessa saudade. A metáfora inicial desse sentimento, "borrão de fogo sujo", revela que ela não é bem vinda: a saudade arde, como o fogo, e por isso se opõe ao ideal-de-felicidade-Caeiro, que se resume às sensações simples 
("Antes isso que ser o que atravessa a vida / Olhando para trás de si e tendo pena..."). A palavra "borrão" surge como um obstáculo à visão clara do mundo.

Como um grande borrão de fogo sujo

O sol posto demora-se nas nuvens que ficam.

Vem um silvo vago de longe na tarde muito calma.

Deve ser dum comboio longínquo.

Neste momento vem-me uma vaga saudade

E um vago desejo plácido

Que aparece e desaparece.

Também às vezes, à flor dos ribeiros,

Formam-se bolhas na água

Que nascem e se desmancham

E não têm sentido nenhum

Salvo serem bolhas de água

Que nascem e se desmancham.

"Saudade" alude a significados que escapam ao mundo sensível, e remete ao movimento saudosista em Portugal, ao qual o antiespiritualismo caeiriano se opõe. Ela é uma elaboração mental do sujeito dos poemas, e, como toda elaboração, deve ser rejeitada. Mas o que Pessoa faz é mais interessante do que meramente omiti-la da constituição de um eu lírico que se quer exclusivamente sensorial. Ele se refere a ela a partir de outra metáfora, "bolhas de água". Ora, essa é uma expressão similar à anterior, e que carrega um segundo elemento, "água", que se sobrepõe, ou apaga, o anterior, "fogo". De modo semelhante, a "bolha" é fugaz, ela estoura, desaparece sem deixar vestígios, ao passo que o "borrão" é a mancha, que suja e permanece. Esse apagamento de uma metáfora através da substituição por outra pode ser referido como um processo de desconotação no texto: a saudade não é mais um sentimento essencialmente humano, e tipicamente português, mas algo insignificante, que facilmente se desmancha, como o orvalho nas flores. Esse é o modo como se caracteriza o mecanismo poético de um "aprendizado de desaprender" na poesia-Caeiro. 
Mas há ainda uma outra metáfora para "saudade" no poema. Por comparação, "sol posto" equivale a "borrão de fogo". Ora, para o sujeito sensitivo, o céu avermelhado do poente é apenas um espaço colorido, sem sol. O sol que se "demora" nas nuvens é, por uma sinédoque, a luz que ele produz refletida nas gotículas de água. O sol já se pôs, e portanto os sentidos não são capazes de apreendê-lo. Se é assim, será possível que um sujeito sem memória atribua o colorido das nuvens no entardecer ao sol? Como vimos, houve algum tipo de operação mental extra-sensorial capaz de conduzi-lo a estabelecer relações de causa e efeito. Hume explicaria isso pelo hábito, mas essa seria uma explicação se aplicada a esse caso, porque melhor serviu a Hume como forma de demonstrar a inexistência de ideias inatas.

Se nos referirmos à hipótese da estátua, de Condillac, talvez possamos iluminar essa questão. É fácil supor que se eu não tivesse memória, se não me restasse nenhuma lembrança das modificações do mundo diante de mim, limitaria a minha atenção a uma única maneira de ser, e a cada turno acreditaria estar sentindo pela primeira vez: "anos inteiros viriam se perder em cada momento presente.”(CONDILLAC, op. cit., p. 65) Assim, para mim seria impossível levar em conta duas sensações. Estabelecer relações entre o que experimento agora e o que experimentei no passado seria algo impensável, porque desconheço o passado, sou um ser aprisionado no presente. $\mathrm{O}$ meu prazer e a minha dor são realidades absolutas, só sou capaz de experimentar uma única sensação de cada vez, e, sob essa condição, jamais desejo ou temo algo. Mas isso nunca se modificaria?

Segundo Condillac, depois de um certo tempo eu desenvolveria capacidades mentais: se experimento várias vezes a mesma sensação, eu me condiciono a um certo modo de sentir, desenvolvo determinadas reações que vão me condicionando a sentir sempre da mesma forma. Se depois experimento uma segunda sensação, desenvolvem-se duas atenções em mim, uma passiva, que se exerce sobre o que está diante de mim, e uma ativa, que se concentra naquela sensação que me deixou impressões.

Seria interessante remeter essa discussão, por meio de um salto temporal, à noção de "condicionamento de respostas emocionais". Eu não pretendo me estender nisso, mas apenas lembrar que a indução de reações foi matéria da psicologia experimental russa, com Pavlov (1957) e da psicologia comportamentalista norte-americana, com Watson (Apud SKINNER, 1985), e 
considerar que é, portanto, pertinente aceitarmos o argumento de que a repetição de uma impressão induz a reações, e que ambas deixam resíduos mentais. $^{3}$

Isso equivale a dizer que depois de um certo período experimentando uma mesma sensação, quando defrontado com um estímulo diferente, eu passo a dividir a capacidade de sentir. Numa primeira etapa, se eu apenas tive duas experiências (a primeira sensação que se repetia, e uma segunda agora), só posso me lembrar daquela outra, e comparar esta com aquela. Mas a minha interação com o mundo me permitirá acumular uma sequência de modificações, e eu, a estátua, agora conservando a lembrança de um grande número delas, serei levado a lembrar preferivelmente as que mais podem contribuir para a minha felicidade: eu me deterei nas sensações que me forneceram maior prazer, e procurarei desprezar as que me provocaram algum tipo de insatisfação, como angústia, por exemplo. (CONDILLAC, op. cit, p. 69) A partir da comparação entre as sensações nasce o julgamento, a atribuição de valor. Para Condillac, essas faculdades são, portanto, fruto das sensações, e não do intelecto, que não existia até então. A sua tese é a de que o intelecto nasce e se desenvolve a partir dos sentidos. Eis, emprestando o termo de Pessoa, o seu sensacionismo. Todas as vezes que a estátua sentir alguma insatisfação, ela inevitavelmente se lembrará de suas sensações passadas: "daí nasce a necessidade ou o conhecimento que ela tem de um bem, cujo gozo julga ser-lhe necessário." (Ibid, p. 71) É desse modo que, segundo o empirista francês, o prazer e a dor determinam as suas (as nossas) faculdades.

Ora, sendo assim, somos levados a pensar que mesmo para o ser puramente sensitivo é impossível não se lembrar, é inevitável desenvolver a memória, e através dela estabelecer relações entre as sensações, compará-las e julgá-las. O procedimento de aproximação da filosofia sensista de Condillac ao ceticismo metafísico de Caeiro torna falsa a contradição intelectual do "mestre dos heterônimos": ele identifica, como vimos, os fenômenos como causa e efeito de outros fenômenos - atribui a um comboio longínquo um silvo vago na tarde calma, ou mesmo ao sol a cor do poente, embora não seja mais capaz de vê-lo no céu.

3. Para mim, até a leitura desses autores, soava pouco convincente a argumentação de Condillac. Por isso, pareceu-me legítima a recensão. 
O mesmo processo está em jogo quando Caeiro se refere, no trecho abaixo, à imagem da aurora.

Isto sinto e isto escrevo

Perfeitamente sabedor e sem que não veja

Que são cinco horas do amanhecer

E que o sol, que ainda não mostrou a cabeça

Por cima do muro do horizonte,

Ainda assim já se lhe vêem as pontas dos dedos

Agarrando o cimo do muro

Do horizonte cheio de montes baixos.

O sol ainda não aparece no horizonte, só se vê o claro do dia, e, no entanto, atribui-se a ele o fenômeno observado. É um exemplo análogo ao anterior. Esses cenários de transição são caros a Pessoa, e constantes em toda a sua poesia. Nesse caso, os recursos estilísticos revestem a aurora de uma conotação quase infantil, porque às crianças é que é típico recorrer a essa estratégia, como pintar o sol no formato de um rosto. Aqui a prosopopéia está de acordo com a ideia que se faz da aurora, que associamos àquilo que é novo, esperançoso ou alegre. Pela manhã, o sol é um menino prestes a pular o muro do horizonte.

Caeiro pode, portanto, identificar aquilo que não apreende sensorialmente; ele estabelece relações. Caeiro se lembra. E se é capaz de se lembrar não há como conter as próprias vontades. O seu mundo não é constituído de unidades absolutas. Eis o que tenta a todo custo evitar, porque Pessoa sabe que a memória conduz à apreensão intelectual do mundo. Se eu sou capaz de me lembrar, torno-me capaz de sentir pelo pensamento, de obter a sensação que o pensamento evoca pela vontade. O intelecto é como se iludisse os sentidos. "O que em mim sente", conforme um dos mais notáveis aforismos do ortônimo, "stá pensando". Estamos já distantes do ideal-Caeiro:

\section{XLI}

No entardecer dos dias de Verão, às vezes,

Ainda que não haja brisa nenhuma, parece

Que passa, um momento, uma leve brisa... 
Mas as árvores permanecem imóveis

Em todas as folhas das suas folhas

E os nossos sentidos tiveram uma ilusão,

Tiveram a ilusão do que lhes agradaria...

Nesse ponto me parece fundamental propor uma pergunta: se Pessoa buscasse objetivamente restringir a poesia d" "O Guardador de Rebanhos" a uma visão de mundo específica, por que então ele introduziria ali poemas em que não só o eu lírico apresenta lapsos ideológicos, como confessa, explicitamente, o raciocínio, o olhar subjetivo e a saudade? Não será Caeiro um ideal de perfeição (isto é, de clareza e simplicidade) que já de partida se mostra irrealizável? Assim continua o poema XLI:

Ah, os sentidos, os doentes que vêem e ouvem!

Fôssemos nós como devíamos ser

E não haveria em nós necessidade de ilusão...

Bastar-nos-ia sentir com clareza a vida

E nem repararmos para que há sentidos...

Mas se for expressão de uma impossibilidade, qual é o sentido dessa poesia? Não há o mais vago sinal de ingenuidade na obra de Pessoa. Ele foi possivelmente o mais fatalmente irônico dos poetas, e cada um dos seus leitores se torna vítima potencial de seus jogos psicológicos, armadilhas teóricas e influências labirínticas. Quando o eu lírico dos poemas-Caeiro afirma que é um guardador de rebanhos, que o rebanho é os seus pensamentos, e que os seus pensamentos são todos sensações, está afirmando que não pensa, que é um colecionador de sensações. O verbo "pensar" é esvaziado: "Penso com os olhos e com os ouvidos / E com as mãos e os pés / E com o nariz e a boca". Mas o eu lírico pensa, pensa que não pensa - essa é a conclusão mais elementar sobre ele. Ou teria Pessoa, segundo sugestão de Leyla PerroneMoisés, apenas escrito haicais. Se é possível identificar elocução nos poemas - um eu lírico que sempre enuncia algo -, então é porque existe um pensamento em ação, é porque nos deparamos com um dizer que se sente, e não com a sensação pura e simples. Ora, mas Pessoa, como Bergson, não haveria se dado conta de que precisava se valer daquilo que recusa nesses poemas 
para poder se comunicar por meio deles? É essa a contradição maior que ele produz (e não em que recai). ${ }^{4} \mathrm{Na}$ contradição a poesia d' "O Guardador de Rebanhos" está instalada, e só na contradição que ela é possível. Eis a estrofe final do poema XLI:

Mas graças a Deus que há imperfeição no Mundo

Porque a imperfeição é uma cousa

E haver gente que erra é original

E haver gente doente torna o Mundo engraçado.

Se não houvesse imperfeição, havia uma cousa a menos,

E deve haver muita cousa

Para termos muito que ver e ouvir...

Num sentido amplo, cantar a imperfeição do mundo significa tomar consciência da impossibilidade de realizar o ideal de indiferenciação - de consubstanciação - entre o eu e o outro. Trata-se, em síntese, da inefabilidade de um arquicaeiro, seja ele um "Caeiro-Zen" ou um "Descobridor da Natureza", tal como o designaram respectivamente Leyla Perrone-Moisés e Maria Helena Nery Garcez. Caeiro não pode ser exclusivamente todo só o seu exterior porque, precisamente, falta-lhe a "simplicidade divina" de um deus pagão. Demasiado humano, Caeiro é incapaz de soltar o lastro da própria subjetividade, e esbarra (mas não esqueçamos que é pelos encontrões que ele se perfaz) na reflexividade de seu próprio corpo, na espiralidade do olhar, na experiência concomitante de observar e ser observado. Entre o olho e o espírito, seu enigma se constitui. Ou, através das palavras luminosas de Merleau-Ponty,

O enigma reside nisto: o meu corpo é ao mesmo tempo vidente e visível. Ele, que olha todas as coisas, também pode olhar para si e reconhecer que está vendo então o "outro lado" do seu poder vidente. Ele vê-se vidente, toca-se tateante, é visível e sensível por si mesmo. (MERLEAU-PONTY, 1989, p. 50)

4. E que põe em relevo a tese luminosa, e tão pouco referida, de Óscar Lopes, segundo a qual o percurso poético de Pessoa encerra um movimento de reductio ad absurdum. Cf. "Fernando Pessoa" in Lopes, Óscar. Entre Fialho e Nemésio - Estudos de Literatura Portuguesa Contemporânea. Vol. 2. Lisboa: Imprensa Nacional / Casa da Moeda, 1987. 
Certa vez, o crítico presencista Adolfo Casais Monteiro afirmou que exigir consistência filosófica de um poeta significa incorrer no mesmo absurdo de se esperar qualidade poética de um filósofo. $\mathrm{O}$ tremendo exercício de apagamento intelectual e de esvaziamento cultural com que nos deparamos n'“O Guardador de Rebanhos" não requer uma representação psicológica, tampouco um nome resguardado pelo apelo de datas e dados biográficos. O interesse que essa fabulação nos desperta é circunstancial, e limitado à ideia de batismo em um tal nível de associação entre arte e vida que conduz fatalmente a atenção para o segundo termo da comparação. Caímos numa armadilha antropológica, possivelmente a mais bem estruturada dessa poesia, quando nos julgamos ser capaz de interpretar que o Caeiro de Pessoa é alguém - alguém, afinal, que não é como deveria ser -, quando, na verdade, o nosso engano está em Pessoa nos fazer pensar que Caeiro realmente devesse ser alguma outra coisa que não uma poderosa construção de estilo.

\section{Referências bibliográficas}

BERGSON, Henri. Essai sur les données immédiates de la conscience. Paris: Presses universitaires de France, 1970.

BORGES, Jorge Luis. Funes, o memorioso. Obras Completas. $5^{\text {a }}$. ed. São Paulo: Ed. Globo, 1999.

CAMUS, Albert. O Mito de Sísifo. Trad. Ari Roitman e Paulina Watch. Rio de Janeiro: Record, 2004.

CONDILLAC, Etienne de. Tratado das Sensações. Trad. Denise Bottmann. Campinas: Editora da Unicamp, 1993.

GARCEZ, Maria Helena Nery. Alberto Caeiro: Descobridor da Natureza? Porto: Centro de Estudos Pessoanos, 1985.

GIL, José. Fernando Pessoa ou a Metafísica das Sensações. Lisboa: Relógio D’Água, 1987.

HERACLITO. I frammenti e le testimonianze. Milano: Arnoldo Mondadori, 1993.

HUME, David. Investigação Sobre o Entendimento Humano. Trad. Leonel Vallandro. São Paulo: Abril Cultural, 1973.

LIND, Georg Rudolf. Teoria Poética de Fernando Pessoa. Porto: Editorial Inova, 1970.

LOCKE, John. Ensaio Acerca do Entendimento Humano. Trad. Anoar Aiex. São Paulo: Abril Cultural, 1973.

LOPES, Óscar. Fernando Pessoa. In: Entre Fialho e Nemésio: Estudos de Literatura Portuguesa Contemporânea. Vol. 2. Lisboa: Imprensa Nacional / Casa da Moeda, 1987. 
MERLEAU-PONTY, Maurice. Fenomenologia da Percepção. Trad. Carlos Alberto Ribeiro de Moura. São Paulo: Martins Fontes, 1999. . O Olho e o Espírito. In: . Textos Selecionados. Trad. Marilena Chauí. São Paulo: Editora Nova Cultural, 1989.

MONTEIRO, Adolfo Casais. Estudos sobre a poesia de Fernando Pessoa. Rio de Janeiro: Agir, 1958.

Presença (30). Ed. Facsimilada. Lisboa: Editorial Caminho, jan.fev. de 1931.

PAVLOV, Ivan Petrovich. Experimental psychology, and other essays. New York: Philosophical Library, 1957.

PLATÃO. Teeteto, o sulla scienza. Milano: Feltrinelli, 1994.

PERRONE-MOISÉS, Leyla. Fernando Pessoa: aquém do eu, além do outro. 3. ed. São Paulo: Martins Fontes, 2001.

PESSOA, Fernando. Páginas Íntimas de Auto-Interpretação. Sel., prefácio e notas de Jacinto do Prado Coelho e Georg Rudolf Lind. Lisboa: Edições Ática, 1966. . Poemas completos de Alberto Caeiro. Intro. de Caio Gagliardi. São Paulo: Hedra, 2011.

SIMÕES, João Gaspar. Vida e Obra de Fernando Pessoa: história duma geração. 6a. Edição. Lisboa: Publicações Dom Quixote, 1991.

SKINNER, B. Ciência e Comportamento Humano. São Paulo: Martins Fontes, 1985.

Recebido em 02 de agosto e aprovado em 15 de setembro de 2010. 